\title{
Parece necesaria una revisión de la Ley de Patrimonio Histórico Español de 1985
}
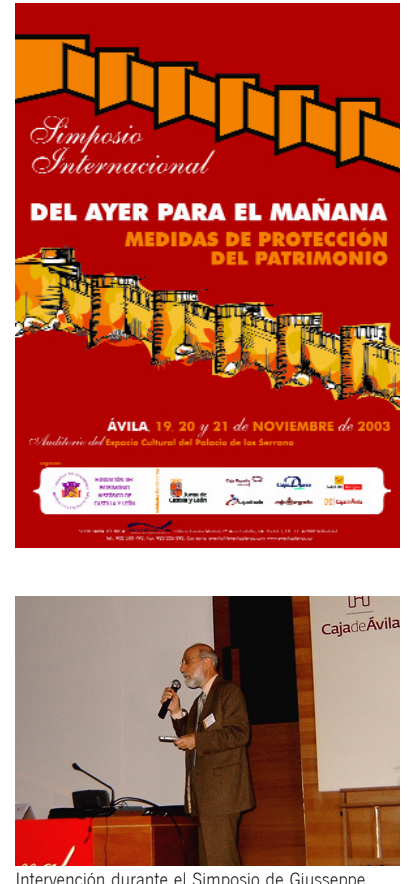

Rasile, del Instituto Italiano del Restausseppe Foto facilitada por Evento Organización de Servicios Plenos
Con el título Del ayer para el mañana. Medidas de protección del patrimonio se celebró en Ávila del 19 al 21 de noviembre un Simposio internacional convocado por la Fundación Patrimonio Histórico de Castilla y León. Se organizaron cinco sesiones de trabajo.

En la dedicada a Legislación participaron Alfredo Pérez de Armiñán de la Real Academia de Bellas Artes de San Fernando, Alfredo Stampa Santiago de la Junta de Castilla y León y Juan Manuel Alegre Ávila de la Universidad de Cantabria, que trataron respectivamente de la Ley de Patrimonio Histórico Español, de la de Castilla y León que recientemente aprobada ha sido el punto de partida del Simposio y de las del resto de las autonomías.

En la sesión La realidad de la protección y la conservación se presentó un estado de la cuestión sobre el patrimonio internacional, el eclesiástico y el arqueológico, temas abordados por Jean-Louis Luxen, ex- Secretario General de ICOMOS, José Félix de Vicente Rodríguez, Asesor General para el Patrimonio de la Archidiócesis de Madrid, y por Ma Ángeles Querol Fernández, de la Universidad Complutense de Madrid.

De las intervenciones en monumentos, escultura y pintura y del préstamo de obras de arte trató la sesión La restauración: sus riesgos en la que intervinieron Valentín Berriochoa, arquitecto del Plan director catedral de Salamanca, Gabriela Garcia Lascuraín, del Instituto Nacional de Antropología e Historia de México, Giusseppe Basile, del Instituto Italiano del Restauro y Manuel Árias Martínez, Subdirector del Museo Nacional de Escultura (Valladolid).

Delitos contra el Patrimonio fue el título de la sesión en la que se estudiaron las actuaciones policiales en defensa del patrimonio y los casos de expolio y en ella intervinieron Antonio Cortés Ruiz como Jefe del Grupo de Patrimonio de la Guardia Civil, Karl Heinz Kind, de la Unidad Policial de Obras de Arte de Interpol, e Ignacio Rodríguez Temiño, de la Junta de Andalucía. Antes, José Ramón Nieto González, de la Universidad de Salamanca, planteó La catalogación artística como herramienta de protección.

La última sesión Teorias y ejemplos presentó dos actuaciones contrapuestas, la restauración de la catedral de Vitoria y la destrucción del teatro romano de Sagunto, siendo los ponentes Juan Ignacio Lasagabáster (Servicio de Patrimonio de la Diputación de Álava) y Pedro Navascués (Palacio de la Real Academia de Bellas Artes).

El Coordinador del Congreso, José Luis Gutiérrez Robledo, presentó una ponencia inicial sobre la protección del patrimonio en la que recordó aquella máxima -nunca suficientemente repetida- según la cual el patrimonio es un legado que tenemos que transmitir a las generaciones venideras, y precisó los objetivos del encuentro: incidir tanto en la obligación legal de conservar y proteger el vario patrimonio, como en los criterios de restauración, así como en las diversas facetas del expolio patrimonial. Como era de prever fueron constantes las lamentaciones por el reciente expolio consentido del Patrimonio de Irak.

Día a día fue surgiendo entre ponentes y participantes un consenso implícito en algunos temas. Respecto a la Ley de Patrimonio de Cultural de Castilla y León de 2002, se valoró lo que tiene de adecuación a la realidad del Patrimonio castellano leonés y que ha tenido muy en cuenta la ley española de 1985 y conocido las otras leyes autonómicas que la han precedido, completando el conjunto de figuras de protección. Pérez de Armiñan y Alegre Ávila plantearon, con matices, un cierto pesar por el olvido en el que -de facto- ha quedado la ley estatal, magnífico instrumento que casi no se empleó, al haber sido pronto sustituida por las posteriores leyes autonómicas. Sin entrar en valoraciones políticas, se ha aceptado nemine discrepante- que parece necesaria una revisión de esa ley y definir un papel cordinador de la administración central.

Este papel coordinador del Estado, no de control de tipo alguno ni de limitación de ninguna facultad autonómica, ha sido reclamado también al plantear la necesidad de definir los modos de conservación y restauración, y una prudente y controlada política de exposiciones temporales y préstamos de obras de arte. También se aceptó la sugerencia de Rodríguez Temiño de limitar con carácter general el concepto de patrimonio impidiendo declaraciones sumamente singulares que no hay modo de encajar en ninguna figura legal.

Desde la ponencia específica de catalogación, las dedicadas al expolio, y al patrimonio eclesiástico, se ha insistido en que el catálogo, el conocimiento de todo lo que tenemos, es urgente necesidad, y la mejor y primera herramienta de protección. Este nuevo catálogo, público y con un modelo similar en toda España, debe incorporar los avances tecnológicos y estar en Internet en una versión reducida del mismo constantemente actualizada.

Hubo acuerdo en plantear que el ámbito de actuación en la protección del patrimonio no puede ser hoy local, es necesario que nuestras perspectivas superen lo local y hasta lo regional, debemos situarnos en perspectivas estatales, 


\section{$014-015$ \\ Noticias y comentarios \\ PH47 - Febrero 2004}

europeas y universales. La Unesco, el Icom e Icomos son referentes imprescindibles.

Unánimemente se ha indicado que la protección, la conservación, la restauración son tareas de equipos multidisciplinares de especialistas que deben actuar perfectamente coordinados.

Importante es apuntar que constantemente se ha proclamado que la protección del patrimonio es tarea de todos los ciudadanos, resaltando la importancia de educar en el conocimiento y el respeto del patrimonio y -muy singularmente- el papel de las asociaciones de defensa del patrimonio (se señaló el gran potencial que suponen los 2.300 poseedores de la tarjeta Mecenas Amigos del Patrimonio de la Fundación del Patrimonio Histórico de Castilla y León). Las asociaciones tienen que abrirse a la sociedad y ellas y las administraciones deben precisar cauces de diálogo. Este último punto se ha relacionado directamente con la reflexión más repetida: el modelo a seguir por quienes estamos comprometidos con la defensa del legado de la memoria patrimonial es el del movimiento en defensa del medio ambiente, de la naturaleza, del patrimonio ambiental, hay que buscar la sensibilización general y hay que partir de la educación y la formación.
Como coordinador del Simposio debo apuntar dos acuerdos obvios más, que quizás no se concretaron en el Salón de sesiones, pero sí en las tertulias siguientes. Preciso es que las distintas leyes se cumplan, y asi se ha insinuado que el Estado asuma todas las competencias que la Constitución, la Ley de patrimonio del 85 y distintas sentencias judiciales han definido; quienes incumplen con las numerosas leyes que defienden el patrimonio deben terminar ante un juez y cumplir las sentencias que sobre ellos recaigan. Las actuaciones sobre edificios monumentales deben cumplir con la legislación española y con los acuerdos internacionales asumidos por España, deben ser acometidas por equipos interdisciplinares y en ellas debe huirse de plantear actuaciones de diseño y relumbrón sobre conjuntos patrimoniales pretextando su restauración. El Simposio escuchó atónito como Pedro Navascués advertía de una posible declaración de BIC del "nuevo teatro de Sagunto" que sortearía la sentencia judicial y legalizaría a posteriori el expolio cometido.

José Luis Gutiérrez Robledo

Universidad Complutense de Madrid

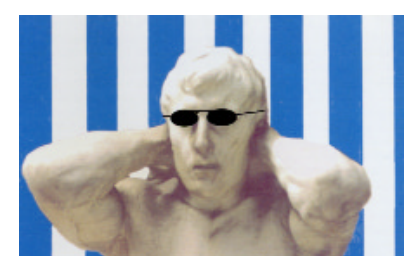

\section{El III Congreso de Historia Antigua de Málaga recupera la memoria de lo clásico}

Entre los días 29 y 31 de octubre de 2003 se celebró el III Congreso de Historia Antigua de Málaga, con el tema monográfico La Tradición Clásica en Málaga (XVI-XXI), organizado por el Grupo de Estudios Historiográficos y el Área de Historia Antigua de la Facultad de Filosofía y Letras de Málaga.

Los dos congresos anteriores se celebraron en 1994 y 1998, dando lugar a dos publicaciones, ambas dedicadas a la historia antigua de Málaga y provincia; la primera planteaba un estado de la cuestión del conjunto de los problemas suscitados entre el siglo VIII a. C. y los comienzos del VIII d. C., y el segundo se centró en el tema del Comercio y Comerciantes en la Historia Antigua de Málaga, en este mismo periodo. Dada la existencia de ambas publicaciones que ofrecen una puesta al día suficientemente sólida sobre todo ello, se pensó en esta ocasión plantear un tema diferente, el de la tradición clásica en Málaga y provincia desde la conquista cristiana de la ciudad a finales del s. XV hasta la actualidad.

El punto de partida es, entonces, el hecho innegable de la presencia del referente del mundo grecorromano en las elaboraciones culturales europeas desde el Renacimiento, sólo paralelizable a lo que supone en el campo más ligado a lo religioso la judeocristiana. Se trataba, entonces, de partir de este hecho y de asumir la perspectiva de que se trata de una zona que, con independencia de presentar una gran riqueza arqueológica desde los fenicios hasta los bizantinos y visigodos, si es significativa no es por su carácter de gran foco cultural, sino precisamente por el hecho contrario: por ser una más de las ciudades andaluzas, españolas 0 europeas en el uso de esa tradición clásica a lo largo del tiempo. Interesaba, en consecuencia, más que la eventual búsqueda de elementos destacados o excepcionales, entender las múltiples presencias, las múltiples actualidades que había supuesto la memoria de lo clásico en este espacio a lo largo del tiempo y hasta el presente.

Se buscó posibilitar un encuentro científico que presentase un panorama amplio de estos usos en todos los campos y momentos del periodo en estudio, siempre en la perspectiva de propiciar debates transversales y multidisciplinares que desbordaran los marcos académicos convencionales en los que se fragmenta un tema tan complejo y multiforme, con la intención de llegar también hasta un presente en el que cabe volver a preguntarse, como en tantos momentos anteriores, sobre qué uso cabe darle a una memoria así de rica y de omnipresente.

Tras una presentación de los objetivos del Congreso a cargo de su director (La Antigüedad viva. 